\title{
COASTAL EROSION TRIGGERED BY POLITICAL AND SOCIO-ECONOMICAL ABRUPT CHANGES: THE CASE OF LALZIT BAY, ALBANIA
}

\author{
De Leo $\mathrm{F}^{1}$, Besio $\mathrm{G}^{1}$, Zolezzi G. ${ }^{2}$, Bezzi M. ${ }^{2}$, Lami I. ${ }^{3}$, Floqi T. ${ }^{3}$
}

\begin{abstract}
Countries that undergo abrupt changes in their political regimes, such as the transition from totalitarianism to systems based on democratic principles, experience socio-economic changes that may also have a direct impact on the transformation and the anthropic pressure applied to the environment. This can ranges from the scale of small communities to larger spatial scales, such as that of a catchment basin. The rise of a liberal society in countries such as the Eastern European nations, often lacks a structure capable of regulating and planning the development of the territory and the use of natural resources, which should be aimed at conciliating the new development needs with the sustainable management of the environment. This paper describes and analyses the extensive coastal erosion that has taken place over the past thirty years in Lalzit Bay, Albania, which may be attributed to the great social and economic transformations that occurred in the country after the fall of Enver Hoxa's communist regime in 1991, and the consequent changes in land use. These led to a significant reduction in the volume of sediment carried by rivers, which was necessary for the morphological equilibrium of the coast and its natural replenishment.
\end{abstract}

Keywords: coastal erosion; coastal management; sustainable development; Lalzit Bay Albania

\section{INTRODUCTION}

We can define "coastal erosion" as the encroachment upon the land by the sea, measured by averaging over a period long enough to be able not to consider the impact of individual storm events (Veloso-Gomes et al., 2006). The morphological dynamics of a coastal system are basically determined by sediments transport processes, due to the action of both the sea and the rivers that outflow in that specific basin. The behaviour of a coast has then to be analysed within the proper space and time scales of the involved physical processes. First of all, when dealing with coastal dynamics, is therefore necessary to identify the "Physiographic Units", lengths of shoreline with coherent characteristics in terms of both natural coastal processes and land use (UNEP, 2008). These units are identified due to the particular morphology of a coastline, its particles'size, petrography, waves' climate and wind characteristics.

Albanian coastline is divided into eight physiographic units. The present work focuses on erosion occurring in coastal physiographic unit n.2, corresponding to the Lalzit Bay, which is situated between Rodoni cape and Pishti i Palles cape nearby Durres (cfr. Figures 1,2).

The research was promoted by the Albanian Ministry of the Environment in order to assess the main causes of the huge coastal erosion that affects the Lalzit Bay's coastline. This is an issue of primary concern, since the interested area is meant to be a pole for the Albanian tourism development policies over the next years.

The goal of this work was to identify the processes that could have played a significant role in controlling the changes in the coastline's position, and to connect the historical trends of coastline evolution with related changes in biophysical and socio-economic processes. We further quantified how the relevant physical as well as biological processes did change over the last thirty years, a reference time span over which lots of significant changes occurred in the country's socio-economical conditions.

The paper is organized as follows: in the first section the investigated area is presented, introducing the socio-economical as well as the environmental Albanian contexts, then specifically focusing on the Lalzit Bay's area. The second section shows procedures and methods adopted to investigate coastal erosion and related biophysical processes. The results of the analysis are reported in the third section. Finally, in the fourth section the conclusions are summarized and the results are discussed.

\footnotetext{
${ }^{1}$ Department of Environmental, Chemical and Civil Engineering, University of Genova, Italy

${ }^{2}$ Department of Mechanical,Environmental and Civil Engineering, University of Trento, Italy

${ }^{3}$ Polytechinc of Tirana, Albania
} 


\section{THE DEVELOPMENT CONTEXT OF ALBANIA}

Over the past twenty years, Albania went through a huge economic development, which contrasts with the previous stagnation related to the totalitarian regime that ruled the country until the early 1990s. So far Albania is still classified as a country with a transitional economy, according to the proposed methodology of the Organisation for Economic Cooperation and Development ("OECD"; oecd.org). Among the main development challenges Albania has to face, the uncontrolled growth of the public debt, the lack of infrastructure and the diffused corruption play a key role and affect its environmental conditions. Albania has still large portions of unexploited land, basically due to the previous limitations imposed by the socialist regime. Such condition is related with a high environmental value and potential, which nowadays it is threatened by the lack of an efficient legislation, still under development. Albania is characterized by a huge urbanization process, implying the need to pay specific attention for a better territorial planning, as it is common in other countries subject to analogous dynamics (Diamantini et al., 2011). After the fall of Enver Hoxa's communist regime, urban growth lasted uncontrolled for almost ten years; then, starting from the early 2000s, urban regulations began to be adopted, but was only with the law n.10119 in 2009 that territorial planning embedded the principles of sustainable development ${ }^{1}$. Along with that, regulations aimed to properly manage the coastal and the fluvial ecosystems were issued: Albania boasts a huge

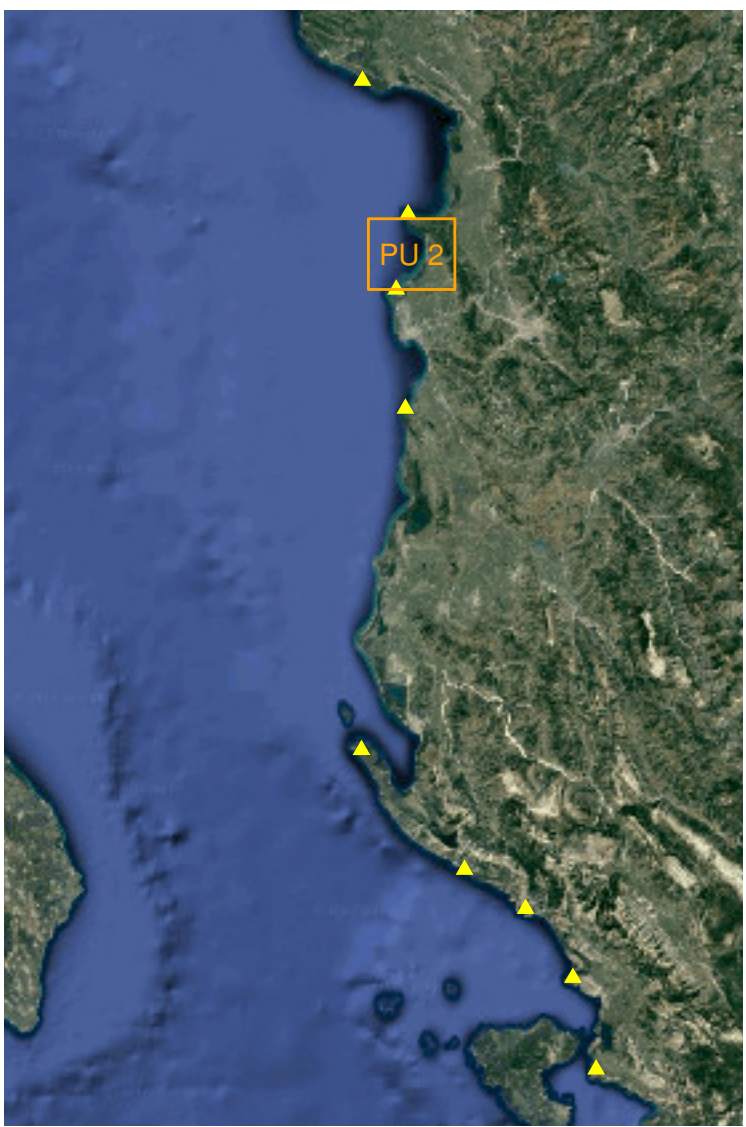

Figure 1: Limits of the Physiographic Units along the Albanian coastline (triangles); PU2 denotes the Physiographic Unit of Lalzit Bay. water availability, thanks to many rivers which produce a yearly total flow of $1200 \mathrm{~m}^{3} / \mathrm{s}$ (assets.panda.org). This is a fundamental resource, particularly with regard to hydro-power generation, agricultural irrigation and many industrial uses. Between 2006 and 2009 , many regulations were promoted to discipline the exploitation of river resources, particularly aimed to rule the growing quarries' activity, since sediments extraction is highly required to sustain the urban development. Lots of improvements were made over the past recent years, but still legislation enforcement happened to be not efficient enough (Cullaj et al., 2005).

\section{Study area: Lalzit Bay}

The Lalzit Bay is located in the northern part of Albania, and being included between two capes it can be considered as an independent physiographic unit (Figure 1). Its coastline is characterized by the mouth of the Erzeni, which is the main river in the basin, and therefore the main source of solid material; moreover, it collects most of the industrial and civil outflows from the Durres as well the Tirana basins, which $46 \%$ of the total Albanian population live in (statistics, 2012).

Over the last century, the coastline of the bay has always changed its shape, particularly nearby the area of the Erzeni's mouth, with both accretion and erosion speed rates ranging between $5 \mathrm{~m} / \mathrm{y}$ and $30 \mathrm{~m} / \mathrm{y}$ (Boçi, 1994; Ciavola, 1999). A marked erosion of the coastline is known to be occurring in the last decade, though a clear quantification of such process and of its related temporal and spatial dynamics is not available so far.

\footnotetext{
${ }^{1}$ Law No. 10119 on land use planning (ecolex.org/details/legislation)
} 


\section{METHODS}

The study has been designed according to different methodological steps. First, a conceptual model linking socio-economical and environmental precesses related to coastal erosion has been identified. Natural processes include the waves action which determines the sand transport along the coastline, whereas human-related processes cause loss of vegetated area due to the uncontrolled urbanization, which in turn implies a huge extraction of water and sediments from the river, to sustain the agricultural irrigation and the production of building material. An investigation procedure was then planned, consisting of the following elements.

To characterize the wave climate of the Lalzit Bay's area, we used a hindcast dataset of 1-hourly sampled wave parameters defined over a 37 years period (1979-2015), provided by the University of Genova (Mentaschi et al., 2013, 2015, www.dicca.unige.it/meteocean). The wave characteristics, simulated in deep water, were then propagated towards the shore using the numerical model SWAN v41.01 (SWAN User Manual, 2004). A long term wave analysis was performed to evaluate the vulnerability of the coastline, with respect to both floods and erosion (Bosom García and Jiménez Quintana, 2011); in addition to deepwater wave data, coastline vulnerability analysis required as an input the geometry of the beaches and the characteristic diameter of their grains. Therefore, during the field campaign, we reconstructed sixteen cross-shore sections along the coast. We collected 5 samples of sand at five different sampling locations aligned along the cross-shore direction for each of the sixteen sections along the coastline, collecting three replicates for every sample, for a total amount of 240 grain size samples. Finally we post-processed the collected data through the software Gradistat (Blott and Pye, 2001).

To evaluate the coastline evolution, a comparison between aerial photo belonging to different periods was carried out, using Landsat images referred to different years over the period 1985-2015. The analysis of the ortophotos also allowed us to estimate the changes in land use over the Lalzit Bay's area (Zatelli, 2013).

One of the main challenges was to quantify the morphological changes that occurred in the Erzeni river, with the aim to assess the potential reduction of sediment loads supplied to the bay. To face the lack of detailed information (of historical and present river characteristics), we collected topographical measurements of eight river cross-sections in the field. Together with a rapid appraisal of the main geomorphic and riparian vegetation properties of the reach, this allowed to roughly estimate the ongoing riverbed incision process, coupled with the computation of related changes in bank-full discharges through the HecRas software (Brunner, 2010). We further tested these results with measured ages of some riparian trees (Salix Alba, Populus, Populus Nigra, Populus Tremula and Robinia), taken at different transversal distances from the main channel, evaluated through dendrochronological analysis on eight cores sampled next to the investigated sections (Douglass, 1919).

Finally, we also referred to the information provided by the local population through a set of structured interviews: this was useful to assess the reliability of our estimations, moreover it allowed us to involve and extend the local people's interest on a topic of high relevance, aiming to enable an active citizens' participation.

Each factor was specifically investigated, finally trying to link and summarize the results over an allembracing and cross sectoral analysis, as recommended by the Mediterranean Action Plan (Pavasovic, 1996, "MAP"). A synthesis of data and methods adopted is shown below, whereas the positions of the field surveys are underlined in Figure 2; the ortophotos were taken thanks to the package "ggmap", developed within the $R$ environment (Kahle and Wickham, 2013). 


\begin{tabular}{|c|c|}
\hline Analysis focus & Data Sources \& Methods \\
\hline \hline coastline & $\begin{array}{c}\text { field surveys - section profiles } \\
\text { Gradistat - grain size distribution }\end{array}$ \\
\hline wave climate & $\begin{array}{c}\text { hindcast analysis } \\
\text { SWAN }\end{array}$ \\
\hline PU & $\begin{array}{c}\text { coastal vulnerability indexes } \\
\text { Landsat images analysis } \\
\text { population interviews }\end{array}$ \\
\hline Erzeni river & $\begin{array}{c}\text { Landsat images analysis } \\
\text { Hec - Ras }\end{array}$ \\
& $\begin{array}{c}\text { field surveys - morphological analysis } \\
\text { field surveys - dendrochronological analysis } \\
\text { population interviews }\end{array}$ \\
\hline
\end{tabular}

Table 1: Summary of data \& methods adopted for the Lalzit Bay's investigation.

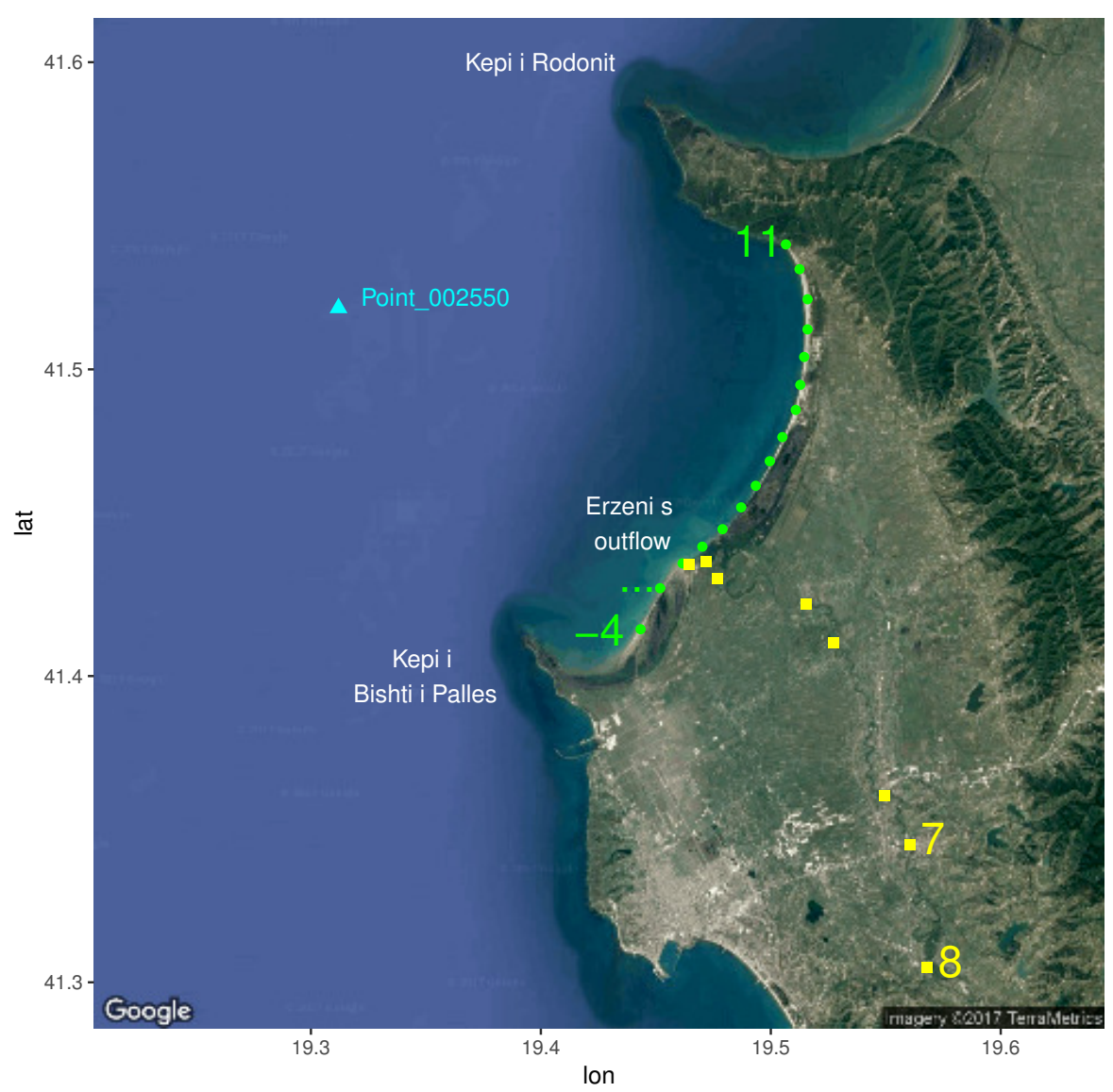

Figure 2: Lalzit Bay, survey sites with sections numbering. Green dots: coastal cross-shore profile. Yellow dots: river surveys. Light blue: wave hindcast. 


\section{RESULTS}

Grain size analysis

Results show that almost every sections is characterized by medium sand, being the median diameters in a $0.55 \mathrm{~mm}-0.64 \mathrm{~mm}$ range (Wentworth, 1922). The only exceptions are related to section $\mathrm{n} .11$, which, lying very close to the rocky cape of Rodoni, is characterized by coarser sediments, and section n.3, where lower grain sizes are most likely due to hitches occurred during the sampling procedures.

\begin{tabular}{|c|c|c|c|c|c|c|c|c|}
\hline section & -4 & -3 & -2 & -1 & 0 & 1 & 2 & 3 \\
\hline \hline$d_{50}[\mathbf{m m}]$ & 0.62 & 0.60 & 0.64 & 0.62 & 0.60 & 0.55 & 0.56 & 0.21 \\
\hline \hline section & 4 & 5 & 6 & 7 & 8 & 9 & 10 & 11 \\
\hline \hline$d_{50}[\mathbf{m m}]$ & 0.63 & 0.61 & 0.59 & 0.62 & 0.58 & 0.61 & 0.58 & 1.47 \\
\hline
\end{tabular}

Table 2: Representative median sediment diameters for the cross-shore sections along the beach.

\section{Wave climate}

The analysis of the characteristic wave climate reveals a clear trend: the main wave incident direction during the summer months is W-NW, while during the other months is S-SW, as shown in Figure 3.
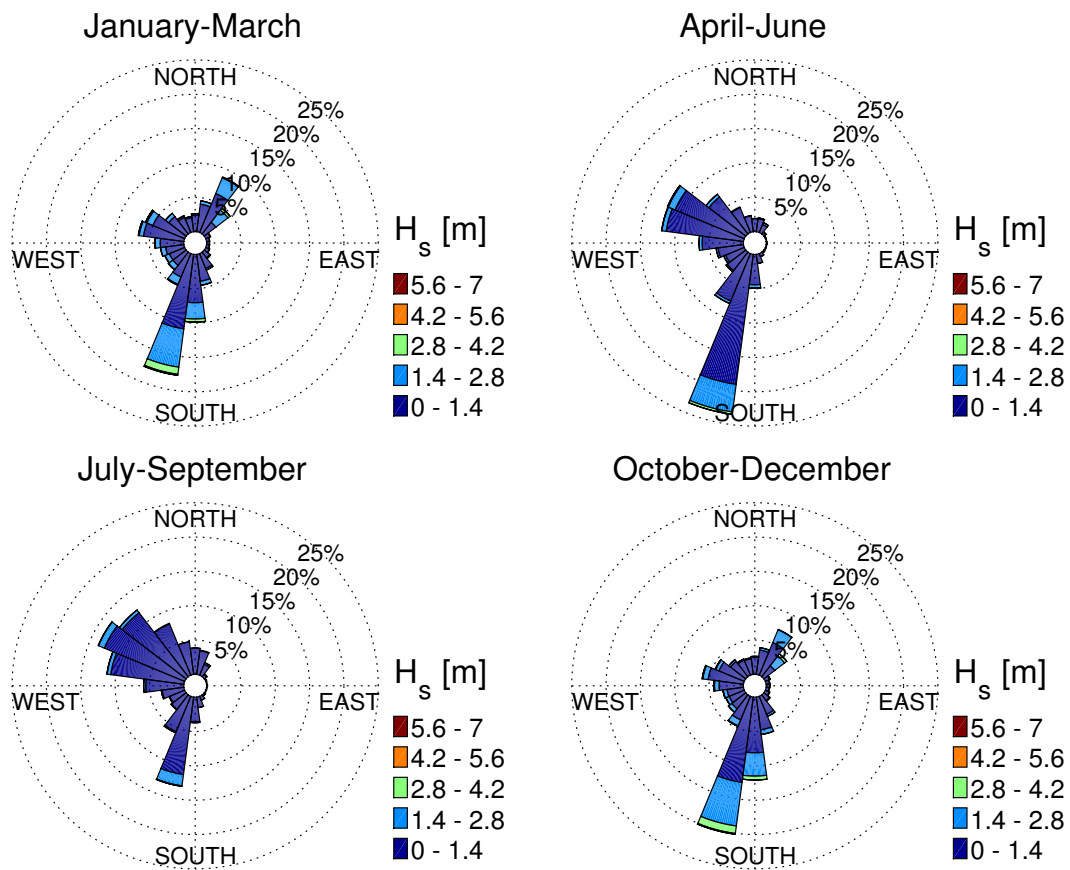

Figure 3: Wave heights with respect to the peak direction for the main seasons of the year.

In order to understand how the seasonality of the wave climate affects the coastline, we investigated how the waves propagate towards the coastline, referring to two significant deep-water incident wave directions. During the winter season, despite the diffraction due to Pishti i Palles cape, waves generally present an angle of attack that deviates from being purely orthogonal to the coastline. This implies that if they come to break, they are able to move sand from the central area of the bay, eventually settling it beside the Rodoni cape. On the other hand, during summer, waves find no obstacles while propagating to shallow waters: they get perpendicularly to the coast, removing material without depositing it somewhere else along the coast.

Looking at the alongshore behaviour of the waves allowed us to infer how sand can be moved by the wave induced currents. Deep-water data, along with the grain size analysis result, were needed in order to assess the natural behaviour of the beach (through the Dean's analysis), as well to evaluate its vulnerability. 
Dean's analysis couples the information from the waves' parameters and the geomorphology of a beach to establish whether if it would naturally grow or retreat (Dean, 2003); in this case, each of the investigated sixteen sections, shows a natural erosion tendency. Anyway, it is worth to mention that the Dean's analysis neither accounts for external sediment discharge nor with the long-shore currents.

As aforementioned, we also evaluated the vulnerability of the beach through two Coastal Vulnerability Indexes ("CVI"); this procedure considers how a beach could face extreme floods and induced erosion, evaluated through Stockdon et al. (2006) and Mendoza and Jiménez (2006) respectively, considering the present geometry of the beach as well as the existing human activities. The results quantify the vulnerability of the beach according to five classes, from "very high" (maximum vulnerability) to "vey low" ("minimum vulnerability"). The results are shown in Figures $4 \mathrm{a}$ and $4 \mathrm{~b}$.
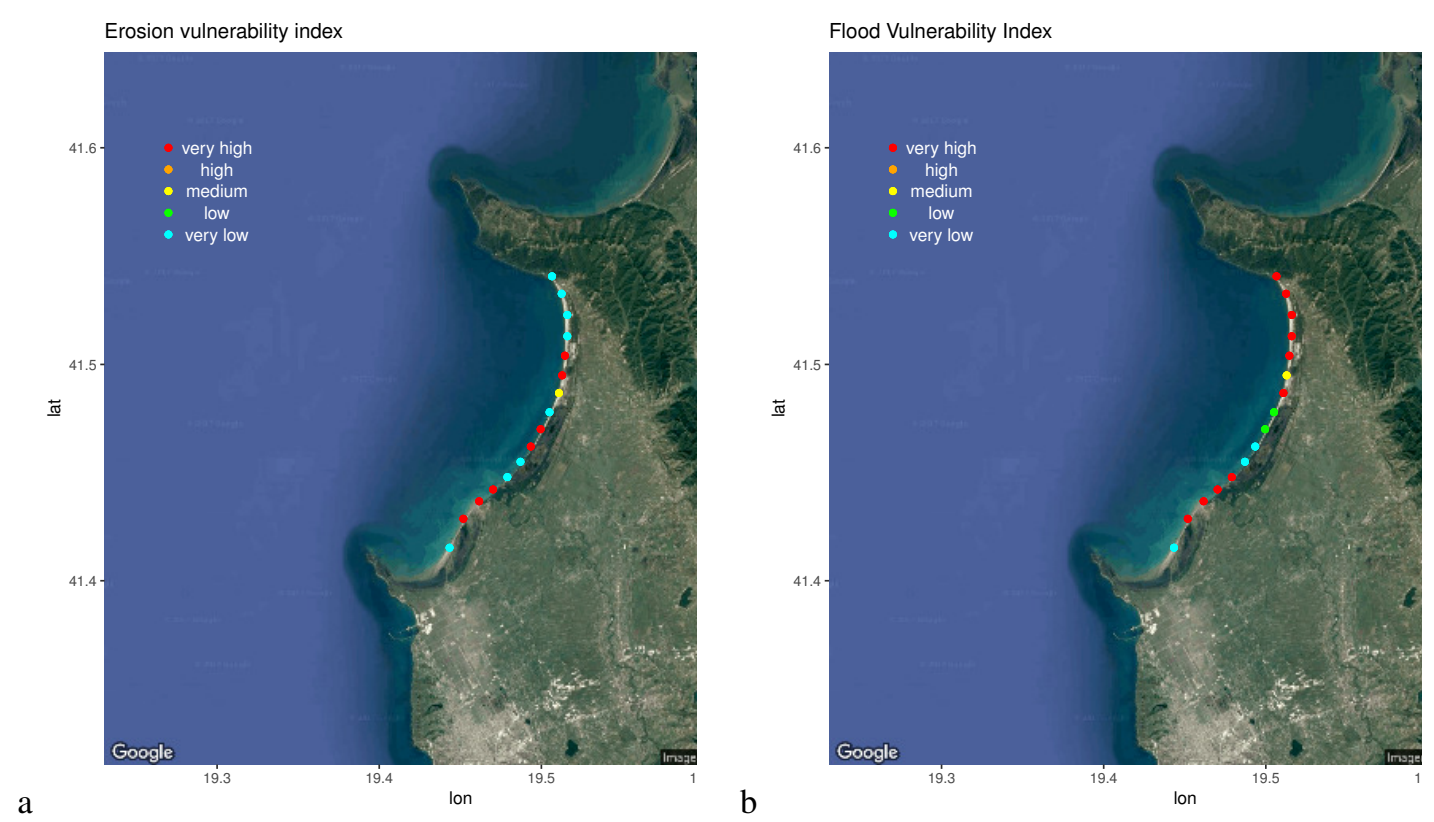

Figure 4: CVI for the Lalzit Bay: a) vulnerability towards storm induced erosion; b) vulnerability towards extreme Run-Up.

The results have to be interpreted carefully. The lack of human activities and infrastructures in the southern part of the Bay implies no threats, also because the sediments dynamics are not interested by the waves' action below the Erzeni outflow, which actually move the sand toward the Pishti i Palle cape. On the other hand, the northern part of the bay shows different behaviour towards erosion and flood vulnerability: in the first case, the larger width of the beach implies low vulnerability, but since the beach's berms were levelled, the flood vulnerability happens to be very high. Finally, the vulnerability is very high in both cases nearby the Erzeni's outflow, as we could expect looking at the movements of the coastline.

\section{Satellite image analysis}

We mainly considered two Landsat images, referred to 1985 and 2015, as they are significant of two relevant historical periods characterised by different socio-economical conditions. Through the analysis of the aerial surveys, we were able to estimate changes in land use along the last thirty years over the Erzeni basin's area.

\begin{tabular}{|c|c|c|}
\hline year & urbanized area $\left[\mathbf{k m}^{2}\right]$ & vegetated area $\left[\mathbf{k m}^{2}\right]$ \\
\hline \hline 1985 & 13.76 & 110.21 \\
\hline 2015 & 24.48 & 97.6 \\
\hline
\end{tabular}

Table 3: Area covered with respect to different land uses in 1985 and 2015. 
As it can be noted from Table 3, the vegetated area was reduced by $11.4 \%$ compared to its 1985 's extension. This partially happened to the detriment of the urbanized one, which increased by almost $78 \%$ of its 1985 's extension. This observation is particularly relevant for our analysis, since this huge urbanization implies the need of construction material, which has been likely mostly picked up from the Erzeni River. It also implies removal of the original forest, which especially along the coast could act as a biofilter against the sand to move inland. Interestingly, the perception the inhabitants of the area got about the changes in land use matches these observations: as most of them reported, the significant reduction of the vegetated area,rapidly increased after 1990, when most of the people left the farms moving to the city of Durres, that consequently increased its extension as the images demonstrate.

The satellite analysis also allowed us to estimate the loss of coastal area that occurred over the last thirty years: as Figure 5 shows, in the central part of the bay the coastal set-back's width was reduced of almost $800 \mathrm{~m}$. Such retreat is mostly pronounced close to the mouth of the Erzeni River.

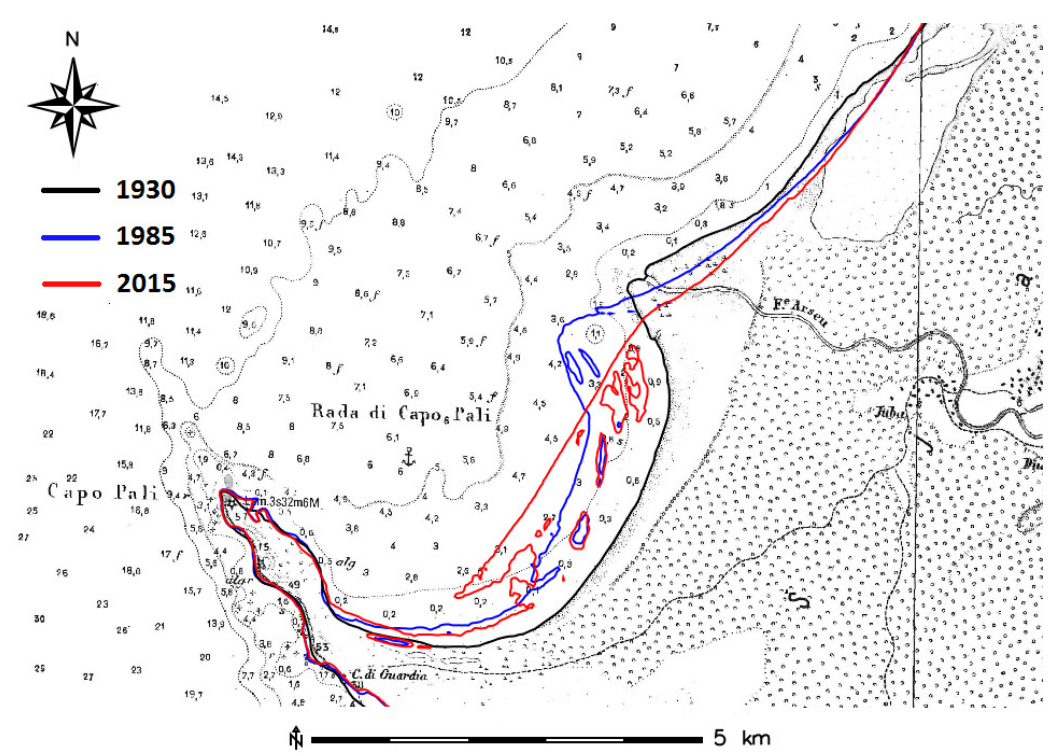

Figure 5: The movements of Lalzit Bay's coastline over the past thirty years.

\section{Sediment transport and channel adjustment in the lower Erzeni river}

A balance between the sediments carried by the river and the ones moved by the waves is required to sustain the coastline position. It's reasonable to assume that such equilibrium has been perturbed in the last decades when the large coastline retreat has been observed. If the river reduces its sediment load, the beach nearby the outflow retreats. An evidence supporting the reduction in the sediment input from the Erzeni River to the coast, was provided by the geomorphic appraisal of the lower course of the river, because historical information on channel adjustment were not available for this study.

Multiple lines of evidence have allowed to confirm the existence of an ongoing incision process in the Erzeni river, despite the absence of historical data on channel evolution. Figure $6 \mathrm{~b}$ shows the river channel at the uppermost section of the examined reach, with clear emergence of bedrock together with residual portions of the former riverbed that can be found at a height of nearly $2 \mathrm{~m}$ above the present low flow water surface level. Bedrock outcrop emergence is a typical sign of riverbed incision as witnessed in other river systems subject to heavy sediment mining, like the Ropa river in Poland (Rinaldi et al., 2005, see Figure 6a). Further downstream, the Erzeni shows a relatively wide river corridor which is mostly occupied by riparian trees, and a narrow channel that must have been incising from the initial low-flow wet channel, as it can be seen in Figure 6c. Interviews with local people indeed suggest a $2 \mathrm{~m}$ incision starting from the early 1990s, which coincides with the termination of the totalitarian regime and with a discontinuity in the development trajectory of the country. Such behaviour is confirmed by a different source of information from the dendrochronological analysis, which indicates that trees in the riparian area depicted in Figure $6 \mathrm{~b}$ are less than 20 years old, an indication that has been further confirmed by local inhabitants of the 
Hardishte bridge area. Finally, Figure 6d shows a representative cross-sectional profile of the river under present conditions (black line) with a low flow channel characterized by unusually small values of the bankfull width to depth ratio, further supporting the ongoing incision trend.
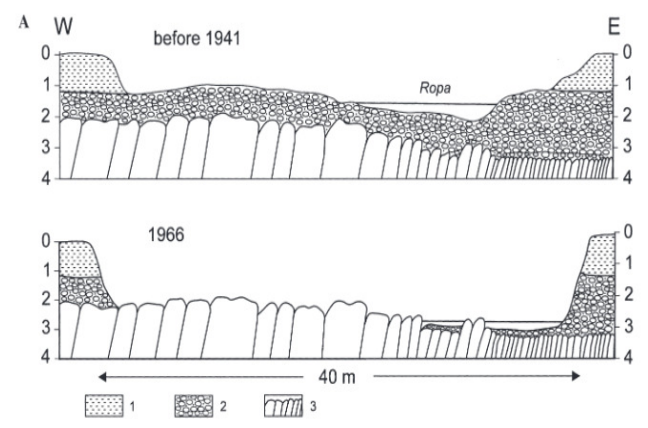

a
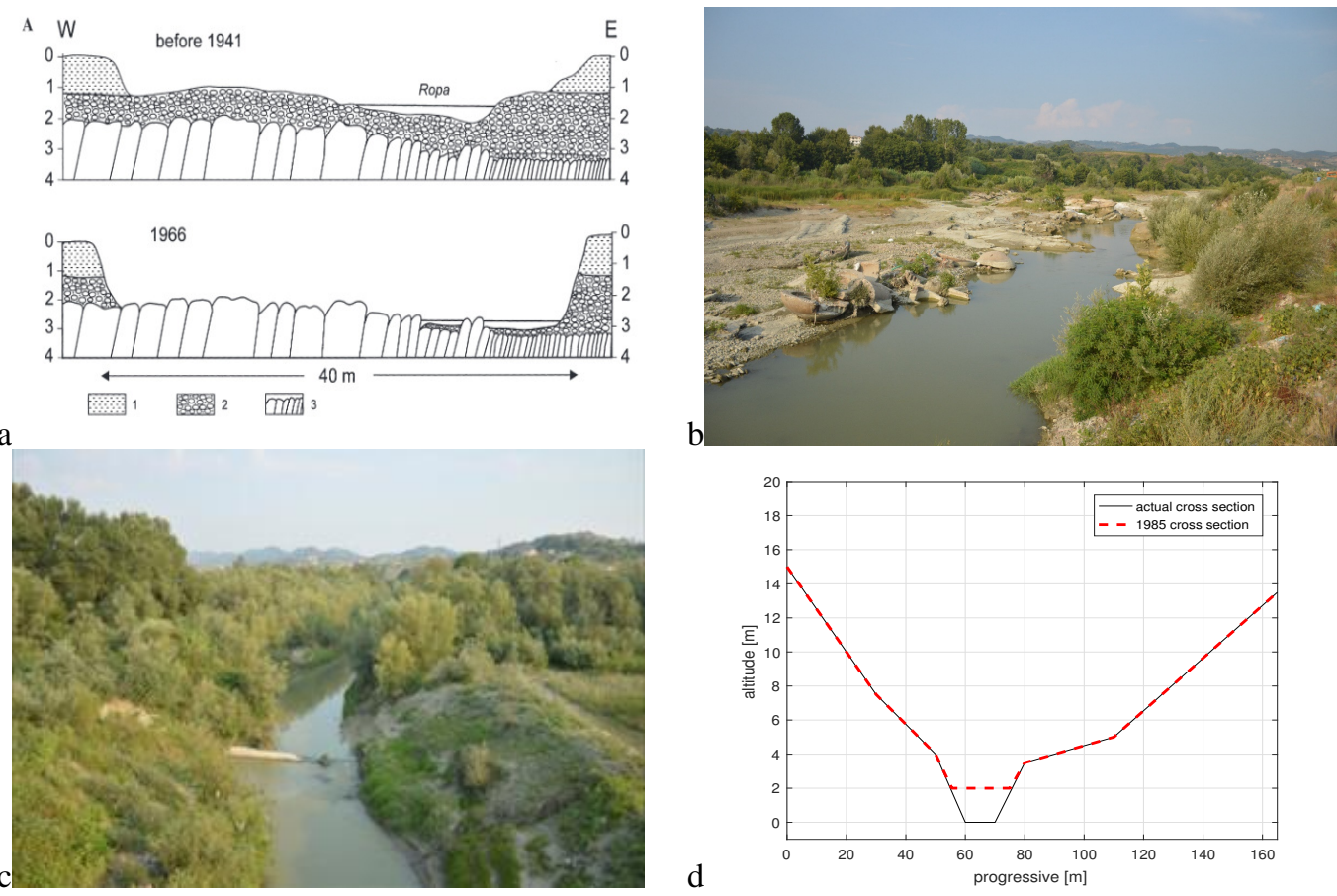

Figure 6: a) sketch of an incising riverbed showing bedrock exposure after incision (Ropa river, Poland, reprinted from Rinaldi et al., 2005); b) Image of the Erzeni riverbed in the uppermost section of the investigated lower reach; c) Image of the Erzeni river close to the Hardiste bridge showing trees encroachment onto its riparian areas and an over-incised low flow channel; d) Representative cross-section (continuous line) with indication of its probable bottom level (dashed line) in the early 1990s before the beginning of intense sediment mining in the Erzeni River.

Consulting the orthophotos of the river's basin, we checked the possible causes of this ongoing incision phenomenon. Nearly forty quarries has been detected: this suggests how the river is heavily deprived of the sediments he carries, threatening its stability. The extraction of material, in fact, in addition to the direct lowering of the picking area, produces an extension of the talweg's incision both upstream and downstream. Excavating alters the longitudinal river profile, increasing the local slope which tends to migrate upstream. Furthermore, the excavation induced cavity acts as a trap for the sediments, interrupting the transport downstream, where erosion becomes prevalent according to the excess of the current energy and the reduced intake of solid material. Riverbed incision in the lowermost reach of the Erzeni River implies an overall reduction of the longitudinal slope, because of the downstream boundary condition fixed by the sea level, and therefore a reduction in its sediment transport capacity, which can be taken as a consistent explanation of the reduced sediment input from the river to the bay. 
Based on the recent review of Floqi and Lami (2015), an estimate of the annual sediment load of the Erzeni river yields a value of about $2.77 \times 10^{6} \mathrm{~m}^{3} / y$. Such estimate only includes the fraction of fine sediments corresponding to the average grain size measured for the cross-shore sections of the bay located nearby the river mouth, and excludes much finer fractions that likely not contribute to the local morphodynamics of the coast. A rough quantification of the reduction of Erzeni's solid flow has then been evaluated starting from the comparison of Landsat images of 1985 and 2015 and from the measured cross-shore sections topography nearby the river mouth. We have hypothesized that the lost volume from the 1985 coast had a pyramidal shape and that its reduction can be linearly splitted over the thirty years (Figure 7). Following these assumptions the yearly loss of volume results in $1.52 \times 10^{6} \mathrm{~m}^{3} / \mathrm{y}$. Comparing these two values suggests a reduction of the sediment load from the Erzeni River to the coast of approximately $50 \%$ of the 1985 value, assuming the coastline nearby the mouth of the river as stable in the past. If we consider instead that the coastline was already retreating in 1985 (see Figure 5), a more reliable reduction close to $20 \%$ would be estimated.

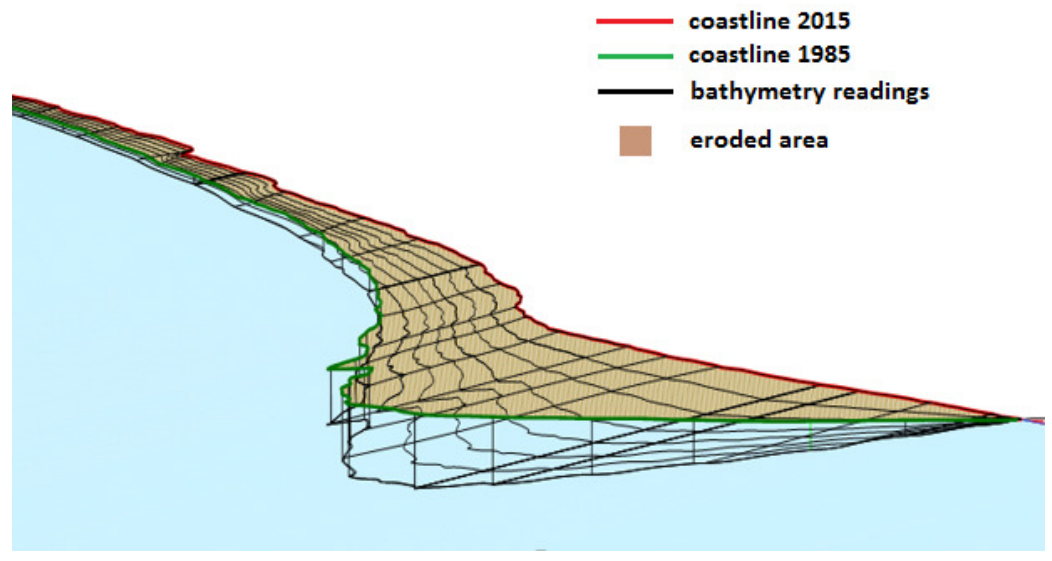

Figure 7: Volume loss on the Erzeni outflow.

\section{CONCLUSIONS}

A coast is a dynamic and fragile environment, subject to many natural and human pressures that contribute to modify its shape over time. Therefore, a coastline usually keeps a dynamic, rather than static equilibrium position, since it is the results of many physical processes that can change in duration and intensity, being either periodic or exceptional, occurring directly next to the sea as well as far away from it. Such dynamic equilibrium may be heavily modified by human activities, which can highly intensify natural phenomena, specially when interventions are not planned in relation to their long term impact.

The Lalzit Bay represents a striking example of such dynamics. Its coastline is very vulnerable to erosion phenomena: it would naturally tend to retreat, as demonstrated by many empirical analysis, if it was not for the natural replenishment provided by the Erzeni river. Sediment input from the Erzeni is crucial to keep a dynamical equilibrium of the coast, through a delicate balance between the sand moved by waves' induced currents and the sand carried by the river. If the load capacity of the river is reduced, it would not be able to supply sediments to the coast anymore, and this is exactly what happened in the last decades in Lalzit Bay. The main cause of such reduced sediment input and related sharp increase in coastal erosion can be associated with heavy sediment mining that has been developing in the Erzeni river, as a consequence from the rapidly increasing demand of construction material, which in turn is triggered by a marked discontinuity in the development path of the country. Our analysis has indeed shown that the Erzeni is witnessing a rapid incision process in the last 20 years, a time span that well matches the abrupt socio-economic changes undergone by Albania after the fall of the Enver Hoxa's regime in 1991. Strong rural to urban migration, rapid economic growth together with a large gap in environmental and land use planning are the likely causes of such increased pressure on riverbeds in the whole country. River incision, and the consequent reduction in sediment transport capacity, are known to be related to flow and sediment 
supply regime alteration, for which sediment mining seem to represent the most important source in the case of the Erzeni, where the river exploitation through reservoir construction is comparatively much more limited.

The observed reduction of the vegetation doesn't seem to have had a direct impact on the beaches' retreat, as the coastal vegetation (which could acts as a filter against the sand to move inland) was not significantly reduced, as the one inland was instead.

Finally, the present study has important implications for coastal zone management in the Lalzit Bay and, in general, for the Albanian coast, which has a strong touristic potential. It shows that coastal development and land use planning for touristic purposes must consider processes occurring in the river catchment even relatively far from the coastline, because these can strongly affect its position and dynamics through a cascade of environmental and physical processes, which are ultimately driven by choices of land use which should be addressed jointly with those related to the coastal areas.

\section{ACKNOWLEDGMENTS}

This study was made thanks to the joined efforts between the University of Trento and the University of Genova (Italy), along with the Polytechnic of Tirana (Albania). A group of both Italian and Albanian students managed the field work under the supervision of five professors belonging to all the Universities involved in the research; the collected data were then analysed by the Italian partners, in the framework of the UNESCO Chair in Engineering for Human and Sustainable Development (DICAM-Unesco Chair).

G. Besio has been funded by University of Genoa through "Fondi per l'Internazionalizzazione" grant.

The authors wish also to thank Daniele Spada for assistance with satellite image analysis.

\section{References}

S. J. Blott and K. Pye. Gradistat: a grain size distribution and statistics package for the analysis of unconsolidated sediments. Earth surface processes and Landforms, 26(11):1237-1248, 2001.

S. Boçi. Evoluzione e problematiche ambientali del litorale albanese. Bollettino della Societa Geologica Italiana, 113(1):7-14, 1994.

E. Bosom García and J. A. Jiménez Quintana. Probabilistic coastal vulnerability assessment to storms at regional scale: application to Catalan beaches (NW Mediterranean). Natural hazards and Earth system sciences, 11(2):475-484, 2011.

G. W. Brunner. Hec-ras (river analysis system). In North American Water and Environment Congress $\mathcal{E}$ Destructive Water:, pages 3782-3787. ASCE, 2010.

P. Ciavola. Relation between river dynamics and coastal changes in albania: an assessment integrating satellite imagery with historical data. International Journal of Remote Sensing, 20(3):561-584, 1999.

A. Cullaj, A. Hasko, A. Miho, F. Schanz, H. Brandl, and R. Bachofen. The quality of Albanian natural waters and the human impact. Environment International, 31(1):133-146, 2005.

R. G. Dean. Beach nourishment: theory and practice, volume 18. World Scientific Publishing Co Inc, 2003.

C. Diamantini, D. Geneletti, and R. Nicchia. Promoting urban cohesion through town planning: the case of Caia, Mozambique. International Development Planning Review, 33(2):169-186, 2011.

A. E. Douglass. Climatic Cycles and Tree Growth: A study of the annual rings of trees in relation to climated and solar activity, volume 1. Carnegie Institution of Washington, 1919.

T. Floqi and S. Lami. Coastline dynamic of the Lalzit bay: a focus on sedimentary crisis from Erzeni river and the scenario for coastal protection, 2015.

D. Kahle and H. Wickham. ggmap: Spatial visualization with ggplot2. The R Journal, 5(1):144-161, 2013. URL http://journal.r-project.org/archive/2013-1/kahle-wickham.pdf.

E. T. Mendoza and J. A. Jiménez. A storm classification based on the beach erosion potential in the catalonian coast. In Coastal Dynamics 2005: State of the Practice, pages 1-11. 2006. 
L. Mentaschi, G. Besio, F. Cassola, and A. Mazzino. Implementation and validation of a wave hindcast/forecast model for the west mediterrenean. In Proc of: 2th International Coastal Symposium, Plymouth, UK, 8-12 April 2013.

L. Mentaschi, G. Besio, F. Cassola, and A. Mazzino. Performance evaluation of WavewatchIII in the Mediterranean Sea. Ocean Modelling, 90:82-94, 2015.

A. Pavasovic. The mediterranean action plan phase ii and the revised barcelona convention: new prospective for integrated coastal management in the mediterranean region. Ocean $\mathcal{E}$ Coastal Management, 31(2): 133-182, 1996.

M. Rinaldi, B. Wyżga, and N. Surian. Sediment mining in alluvial channels: physical effects and management perspectives. River Research and Applications, 21(7):805-828, 2005.

E. statistics. Population and housing census 2011, 2012.

H. F. Stockdon, R. A. Holman, P. A. Howd, and A. H. Sallenger. Empirical parameterization of setup, swash, and runup. Coastal engineering, 53(7):573-588, 2006.

SWAN User Manual. Swan cycle iii, version 40.41. Delft University of Technology, 2004.

M. UNEP. ICZM Protocol in the Mediterranean. available at: www.pap-thecoastcentre.org, 2008.

F. Veloso-Gomes, F. Taveira-Pinto, L. Das Neves, and J. Pais-Barbosa. Eurosion-a european initiative for sustainable coastal erosion. Pilot Site of River Douro-Cape Mondego and case studies of Estela, Aveiro, Caparica, Vale do Lobo and Azores. IHRH, Porto, Portugal, 2006.

C. K. Wentworth. A scale of grade and class terms for clastic sediments. The Journal of Geology, 30(5): 377-392, 1922.

P. Zatelli. Gestione delle immagini con GRASS, 2013. 